\title{
RELAÇOES ENTRE POTENCIAL MATRICIAL NO SOLO E COBERTURA VEGETAL EM UMA ESTAÇÃO EXPERIMENTAL, UBERLÂNDIA - MG
}

\section{Relations between potential matrix in soil and plant cover in an experimental station, Uberlândia - MG}

\author{
José Fernando Rodrigues Bezerra \\ fernangeo@yahoo.com.br \\ Pesquisador, LAGESOLOS / UFRJ \\ Antônio José Teixeira Guerra \\ antoniotguerra@gmail.com \\ Departamento de Geografia - UFRJ \\ Silvio Carlos Rodrigues \\ Instituto de Geografia - UFU \\ silgel@ufu.br
}

Artigo recebido em 15/06/2011 e aceito para publicação em 07/02/2012

RESUMO: Faz-se neste artigo uma análise sobre a relação entre o potencial matricial e a cobertura vegetal em uma estação experimental na Fazenda do Glória, Uberlândia- MG, com base nos dados obtidos nos tensiômetros e na fotocomparação. Foram adotados os seguintes procedimentos: a. Construção de duas parcelas de $10 \mathrm{~m}^{2}$ cada, uma com Solo Exposto (SE) e outra com Geotêxteis e Gramíneas (SG); b. A análise granulométrica dos sedimentos foi baseada na proposta da EMBRAPA; c. Monitoramento de duas baterias de tensiômetros nas parcelas com solo exposto e com geotêxteis em diferentes profundidades (15, 30, 80 e $120 \mathrm{~cm}$ ), com o auxílio de um tensímetro digital INFIELD 5; e d. Fotocomparação com classificação supervisionada usando software de sensoriamento remoto. Os resultados foram divididos em três fases: 1. na fase 1 , a ocupação da cobertura vegetal variou entre 0 a $6,4 \%$, destacando-se o tensiômetro de 120 $\mathrm{cm} \mathrm{cm}$ na parcela com geotêxteis, que atingiu $-20 \mathrm{kPa} ; 2$. na fase 2 , com uma taxa de ocupação variando entre $15,2 \%$ a $59,4 \%$ na parcela com geotêxteis e gramíneas, o potencial matricial chegou a $-32,4 \mathrm{kPa}$ na profundidade de $15 \mathrm{~cm}$; e 3 . na fase 3, com uma taxa de ocupação da gramínea entre $63,9 \%$ a $100 \%$ , cita-se o tensiômetro de $30 \mathrm{~cm}$, que chegou a $-67 \mathrm{kPa}$.

Palavras-chave: Potencial matricial, cobertura vegetal e geotêxteis.

ABSTRACT: The aim of this research is to analyse the relationship between soil matrix potential and vegetation cover on an experimental station in the Gloria Farm, Uberlândia Municipality, Minas Gerais State, taking into consideration the data from tensiometers and photo comparison. We have been using the following procedures: a. two plots were set up, with $10 \mathrm{~m}$ square, one with bare soil and another one with geotextile and grass; $b$. Granulometric analyse was based on EMBRAPA; $c$. Monitoring of two tensiometers sets on geotextile and grass plot in different depths $(15,30,80$ e $120 \mathrm{~cm})$, it was used the INFIELD 5 digital tensimeter; and d. Photo comparison data from supervised classification using remote sensing software. The results were split up into three periods: the first one, vegetation cover index ranged from 0 to $6.4 \%$ and soil matrix potential reached $-20 \mathrm{kPa}$ in $120 \mathrm{~cm}$ depth on geotextile plot; the second one, grass cover 
ranged from $15.2 \%$ to $59 ., 4 \%$ on geotextile plot and soil matrix potential achieved $-32 \mathrm{kPa}(15 \mathrm{~cm})$; and finally, the third one, when vegetation cover index ranged from $63.9 \%$ to $100 \%$ and matrix potential reached $-67 \mathrm{kPa}$ in $30 \mathrm{~cm}$ depth 30 .

Key-words: Soil matrix potential, vegetation cover index and geotextile.

\section{INTRODUÇÃO}

O conhecimento sobre a dinâmica superficial e subsuperficial da água no solo constitui uma importante ferramenta no processo de identificação, análise e recuperação de áreas degradadas por erosão. A dinâmica interna da água no solo revela uma relação de diversos fatores que controlam o componente hídrico, como o clima, propriedades físicas do solo, tensão, sistema radicular da vegetação, macro e micro fauna e uso do solo.

Para obtenção desses dados de disponibilidade hídrica alguns aparelhos são utilizados, destacando-se os tensiômetros, que são instrumentos que medem a tensão com que a água é retida no solo em seus espaços porosos de diferentes diâmetros (macro e microporos), devido à capilaridade que é um fenômeno físico responsável pela descida e subida do nível de água no solo, através dos condutos capilares, gerando uma pressão negativa na interface entre a água e as partículas sólidas do solo, denominada de potencial matricial.

O potencial matricial está diretamente ligado à umidade, quanto mais úmido o solo, maior será o seu potencial. Segundo Reichardt (1985, p. 122) "a descrição matemática do potencial matricial é bastante difícil e sua determinação é normalmente experimental". Dentre os instrumentos mais utilizados para a medição da pressão negativa (potencial matricial) no solo estão os tensiômetros.

De acordo com Coelho \& Teixeira (2004), esses aparelhos se baseiam na "Formação de um equilíbrio entre a solução do solo e a água contida no interior do aparelho, através de uma cápsula porosa que entra em contato com o solo. Caso a água do solo esteja sob tensão, ela exerce uma sucção sobre o instrumento, retirando água deste, fazendo com que a pressão interna diminua. Como o instrumento é vedado, ocorre à formação do vácuo e a leitura no tensímetro fornece o potencial matricial da água no solo“.
Com o potencial matricial pode-se também determinar o grau de saturação da água no solo. Quanto maior a saturação, menor será a capacidade da água em se infiltrar e mais rápida será a geração do escoamento superficial. De acordo com Guerra \& Guerra (1997), o escoamento superficial ocorre quando: "O solo se torna saturado, e sua capacidade de infiltração na superfície do solo é excedida e não consegue mais absorver água. Em solos desprovidos de cobertura vegetal, a formação do escoamento superficial ocasiona a produção de sedimentos, dando início a processos erosivos, tais como sulcos, ravinas e voçorocas".

O potencial matricial no solo é diretamente influenciado pelo sistema radicular da vegetação, no caso desta pesquisa, utilizou-se o capim Baquiária, que segundo as considerações de Crispim \& Branco (2002), o gênero Brachiaria possuem cerca de 90 espécies, comumente chamados de braquiária, têm distribuição marcadamente tropical, tendo como centro de origem primário a África Equatorial. No Brasil, como forrageira é conhecida desde a década de 1950. Conta-se que as braquiárias entraram no Brasil juntamente com os escravos, pois serviam de colchão nos navios negreiros. As gramíneas do gênero Brachiaria são largamente utilizadas em pastagens na América Tropical. As braquiárias são os capins mais plantados no país, sendo utilizados nas fases de cria, recria e engorda dos animais.

Sobre a influência das gramíneas na água do solo Coelho Netto (2001) ressalta que: "Uma vez atendida a demanda (sucção das raízes e solo) das gramíneas, a água excedente pode gerar fluxos de "tronco", como extensão dos fluxos d'água provenientes diretamente das folhas. A convergência das folhas em direção a um núcleo comum de enraizamento propicia maior favorecimento à produção do chamado fluxo de tronco, o qual, em conjugação com o sistema radicular da gramínea, implicará sensíveis variações espaciais das quantidades de precipitações terminais que penetram à superfície mineral".

As águas das chuvas se acumulam nas folhas 
das gramíneas, e essas convergem para um núcleo comum ("Tronco"), que gera um fluxo de água até atingir a superfície. Esse fluxo do "tronco" nas gramíneas, quando atinge o solo, pode infiltrar, podendo ser absorvida pelas raízes das plantas ou alimentar o lençol freático. $\mathrm{O}$ solo estando saturado pode ocorrer à formação de poças e posteriormente o escoamento superficial.

Em relação à presença da cobertura vegetal Pinto et al (1976) considera que: "Ela atenua ou elimina a ação da compactação ocasionada pelo efeito splash e permite o estabelecimento de uma camada orgânica em decomposição que favorece a atividade escavadora de insetos e animais. A cobertura vegetal densa favorece a infiltração, pois dificulta o escoamento superficial das águas. Cessada a chuva, retira a umidade do solo, através das suas raízes, possibilitando maiores valores da capacidade de infiltração no início das precipitações".

Nesse sentido Buckman \& Brady (1976) enumera alguns fatores vegetais e climáticos que exercem influência marcante sobre a quantidade de água que as plantas podem absorver com eficiência em um determinado solo: Sistemas radiculares, resistência à seca, assim como estágio e intensidade de crescimento se constituem em fatores vegetais de grande importância. Temperatura e umidade do ar são variações climáticas que exercem influência sobre a eficiência na utilização da água no solo.

A área de estudo localiza-se na Fazenda Experimental do Glória, município de Uberlândia - MG (Figura 1), situando-se no Domínio dos Planaltos e Chapadas da Bacia Sedimentar do Paraná (Formação Marília), com relevo tabular, levemente ondulado, com altitude inferior a $940 \mathrm{~m}$. Os solos são ácidos e pouco férteis, tipo Latossolo Vermelho, com textura argilo-arenosa. O clima da região do Triângulo Mineiro é do tipo Aw, possuindo um inverno seco e um verão chuvoso. Os principais tipos fisionômicos da região do cerrado são: vereda, campo limpo, campo sujo ou cerradinho, cerradão, mata de várzea, mata galeria ou ciliar e mata mesofítica (CARRIJO E BACCARO, 2000). Faz-se uma análise sobre a relação entre o potencial matricial e a cobertura vegetal em uma estação experimental, com base nos dados obtidos nos tensiômetros e fotocomparação.
Figura 1 - Mapa de localização da área de estudo.

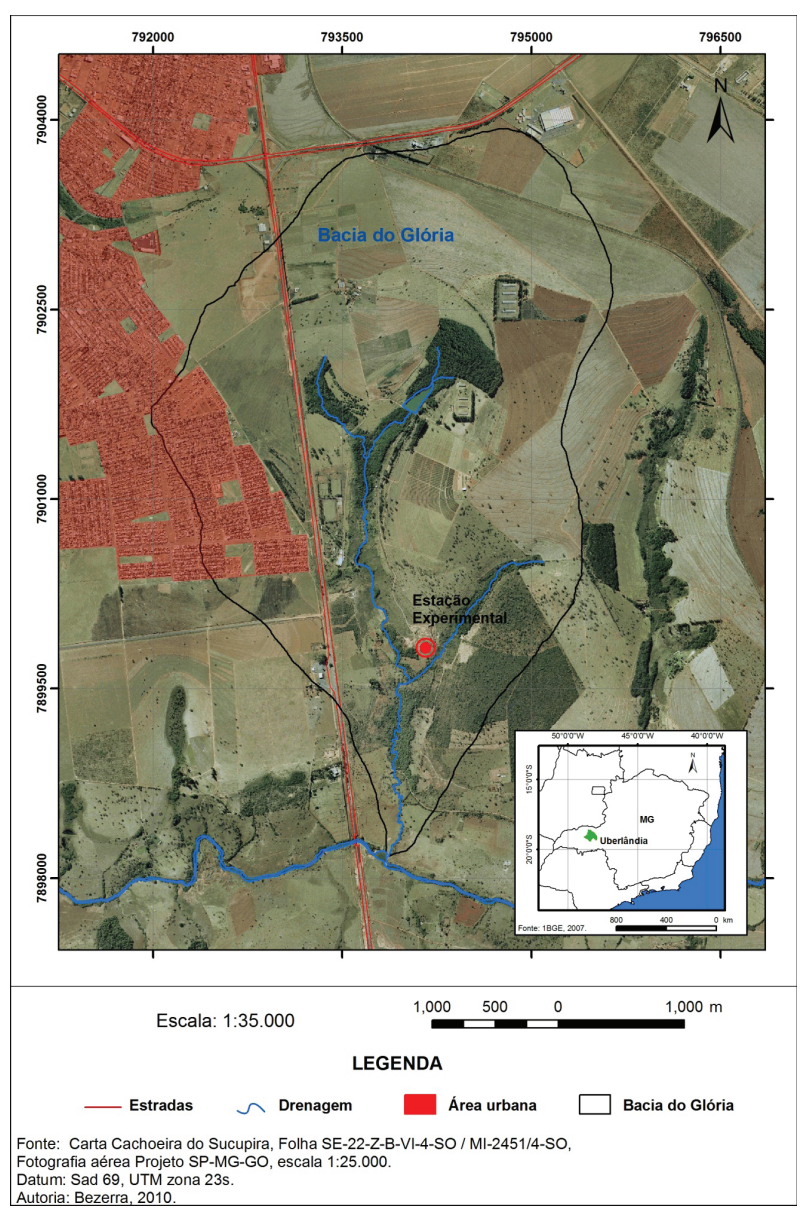

\section{METODOLOGIA}

\section{A estação}

A estação experimental foi montada na Fazenda Experimental do Glória, com duas parcelas de $10 \mathrm{~m}^{2}$ cada, uma com Solo Exposto (SE) e outra com Geotêxteis e Gramíneas (SG), com $12^{\circ}$ de declividade (Figura 2). A área da estação apresenta um regolito homogêneo e compactado, na qual foi necessária a correção com $5 \mathrm{~kg}$ de NPK (fertilizante mineral) e $20 \mathrm{~kg}$ de calcário para o $\mathrm{pH}$ na parcela com geotêxteis. Foi utilizado $1 \mathrm{~kg}$ do capim-braquiarão (Brachiaria brizantha). Na parte inferior das parcelas foram colocados dois galões com 1001 de capacidade. Neste trabalho, foram utilizadas 40 geotêxteis $\left(50 \mathrm{~cm}^{2}\right)$ confeccionados artesanalmente a partir da fibra do buriti. 


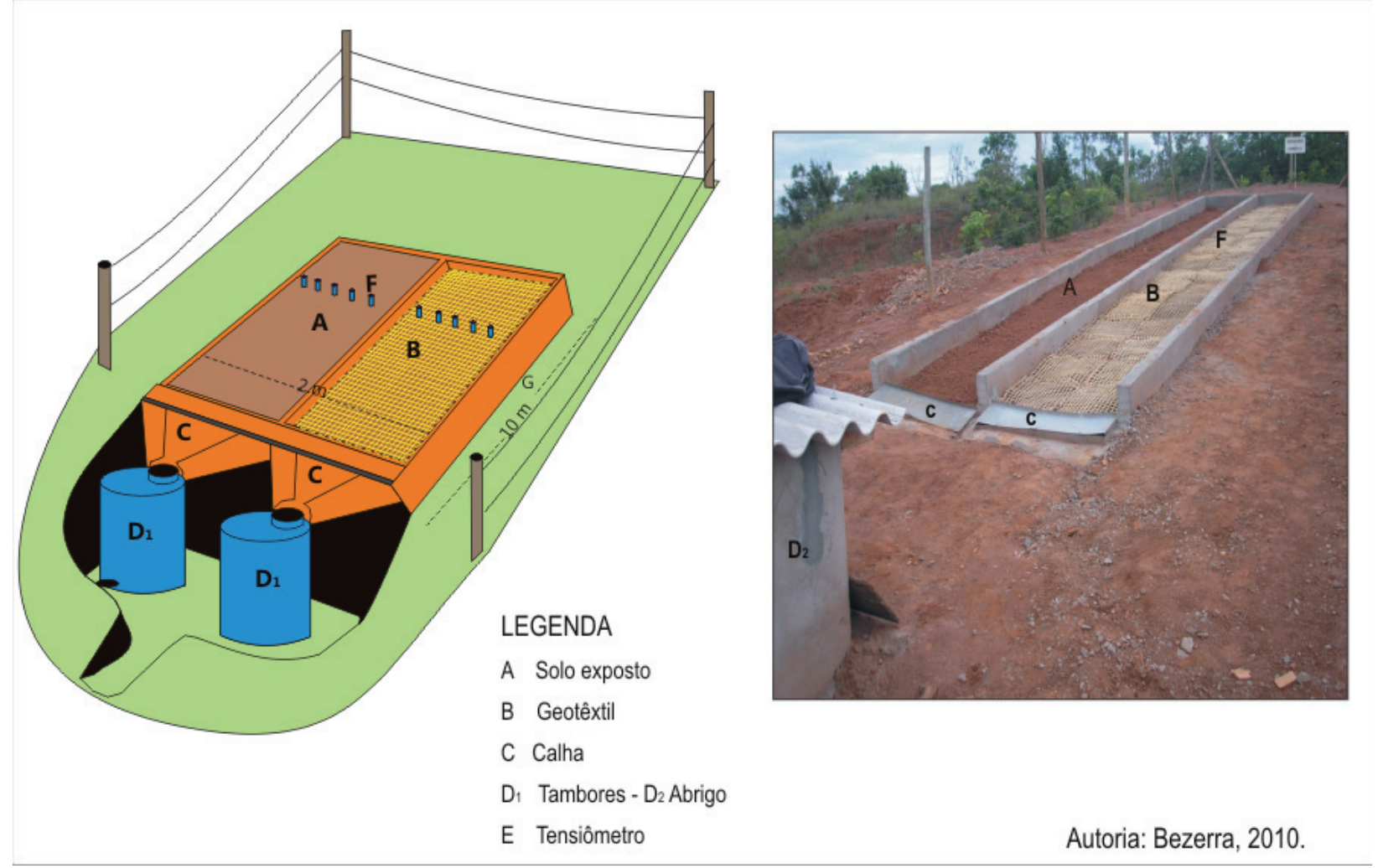

\section{Granulometria}

A análise granulométrica dos sedimentos foi baseada na proposta da EMBRAPA (1979). Os sedimentos coletados foram peneirados manualmente na peneira de $2 \mathrm{~mm}$ para separação das frações entre seixos e a fração fina (areia, silte e argila), sendo necessário $20 \mathrm{~g}$ de material para a realização da análise. Posteriormente foram utilizados $100 \mathrm{ml}$ de água destilada e $15 \mathrm{ml}$ de hidróxido de sódio $(\mathrm{NaOH})$ para desagregação das partículas areia, silte e argila, com o auxílio de uma mesa agitadora durante 15 horas.

As amostras foram lavadas com água destilada na peneira de $0,053 \mathrm{~mm}$, para a separação entre areia e as frações mais finas (silte e argila). Os cadinhos com areia foram levados a estuda a $110^{\circ} \mathrm{C}$, durante $4 \mathrm{~h}$, e depois foram separadas as frações em areia grossa e fina com a peneira de $0,210 \mathrm{~mm}$. A determinação da fração silte e argila foi baseada no método de pipetagem, com auxílio de uma pipeta $(25 \mathrm{ml})$, proveta $(100 \mathrm{ml})$ e um agitador de amostra manual.

\section{Tensiometria}

Na estação experimental, foram instaladas duas baterias de tensiômetros nas parcelas com solo exposto e com geotêxteis em diferentes profundidades $(15,30$, 80 e $120 \mathrm{~cm}$ ), e suas respectivas leituras foram realizadas com o auxílio de um tensímetro digital INFIELD 5. Os tensiômetros foram instalados no sentido perpendicular ao declive da parcela, sendo suas leituras realizadas em cada 48 horas e seus respectivos dados anotados em uma ficha de campo, devido ao não armazenamento do tensímetro. Essas informações foram digitadas e tratadas com o auxílio do software Excel 2000.

\section{Fotocomparação com classificação supervisionada}

A fotocomparação no experimento foi feita através da classificação supervisionada, a partir das ferramentas oferecidas pelo software ENVI 4.0. A taxa de crescimento da cobertura vegetal foi acompanhada semanalmente a partir de fotografias horizontais do mes- 
mo ponto numa área de $1 \mathrm{~m}^{2}$ na parcela com geotêxteis, entre os dias 18 de dezembro de 2005 a 18 de fevereiro de 2006, com auxílio de uma máquina digital $4.0 \mathrm{mp}$, marca OLYMPUS.

$\mathrm{Na}$ área amostral da parcela foi colocado um marco, que com o auxílio da função de enquadramento disponível no display na máquina digital, foi possível tirar fotografias sempre na mesma área de superfície, graças à regulagem do enquadramento do visor em relação ao marco na parcela. As fotografias foram obtidas a uma altura de $1,5 \mathrm{~m}$ do terreno com uma resolução de 2940 x 2340 pixels, sem utilização de tripé para a máquina. As fotografias foram copiadas para o computador e processadas no software ENVI 4.0.

As 17 fotografias obtidas neste período foram tratadas segundo os procedimentos adotados por Azevedo et al (2005), que aplicaram à técnica em uma área sob processo de recuperação ambiental. Os referidos autores adotaram no seu estudo a classificação supervisionada, sendo os mesmos procedimentos utilizados para o processamento de imagens de satélites. As classes selecionadas para a utilização do método Maximum Likilihood nas fotografias foram geotêxtil, solo exposto e vegetação.

\section{RESULTADOS}

Para um melhor entendimento sobre as relações entre o potencial matricial e a cobertura vegetal no experimento, os dados foram organizados com base na fotocomparação e divididos em três grupos, a saber: Geotêxteis (Fase 1); geotêxteis e gramíneas (Fase 2); e gramíneas (Fase 3). Para uma análise mais precisa dessa relação, fez-se necessário a caracterização granulométrica do material nas diferentes profundidades do solo, onde foram instalados os tensiômetros $(15,30,80$ e $120 \mathrm{~cm})$.

Na profundidade de 15 a $30 \mathrm{~cm}$, há o predomínio de areia fina (48,7\%), seguida de $22,4 \%$ de argila, $19,7 \%$ de areia grossa, e $9,1 \%$ de silte. Entre 80 a 120 $\mathrm{cm}$ de profundidade, os solos apresentaram granulometria mais grosseiras com $45 \%$ de areia grossa, $31 \%$ de areia fina, $14,3 \%$ de argila e $9,6 \%$ de silte. Os dados apresentados indicam um solo superficial $(15$ a $30 \mathrm{~cm})$ com granulometria mais fina e compactado, o que poderia interferir, aliado a outros fatores, no processo de infiltração e no crescimento das gramíneas, enquanto na profundidade de 80 a $120 \mathrm{~cm}$, os materiais são mais grosseiros, podendo promover a passagem da água, facilitado pela malha de raízes (Quadro 1).

Quadro 1 - Granulometria dos solos nas diferentes profundidades dos tensiômetros.

\begin{tabular}{|c|c|c|c|c|c|}
\hline \multicolumn{7}{|c|}{ Tensiometros Solo Exposto } \\
\hline Profundidade & Argila & Silte & Areia Fina & Areia Grossa & Areia total \\
\hline $15 \mathrm{~cm}$ & 22.4 & 8.3 & 49.8 & 19.5 & 69.3 \\
\hline $40 \mathrm{~cm}$ & 22.5 & 10 & 47.6 & 19.9 & 67.5 \\
\hline $80 \mathrm{~cm}$ & 13.5 & 12.1 & 31.6 & 42.8 & 74.4 \\
\hline $120 \mathrm{~cm}$ & 15.2 & 7.2 & 30.4 & 47.2 & 77.6 \\
\hline \multicolumn{7}{|c|}{ Tensiometros Solo Geotextil } \\
\hline Profundidade & Argila & Silte & Areia Fina & Areia Grossa & Areia total \\
\hline $15 \mathrm{~cm}$ & 21.2 & 9.9 & 49.5 & 19.4 & 68.9 \\
\hline $40 \mathrm{~cm}$ & 22.3 & 10.5 & 49.8 & 17.4 & 67.2 \\
\hline $80 \mathrm{~cm}$ & 13.5 & 12.1 & 31.6 & 42.8 & 74.4 \\
\hline $120 \mathrm{~cm}$ & 15.2 & 7.2 & 30.4 & 47.2 & 77.6 \\
\hline
\end{tabular}

Org. do autor.

A primeira fase tem início com a aplicação dos geotêxteis e tensiômetros no dia 18 de novembro de 2005 e finalizada no dia 19 de dezembro de $2005 \mathrm{com}$ uma taxa de ocupação da cobertura vegetal de $6,4 \%$ da área amostral (Figura 3). Os totais pluviométricos registrados nesse período foram de $345.6 \mathrm{~mm}$. Essa etapa caracteriza-se pela ausência e/ou início do desenvolvimento da cobertura vegetal.

Ressalta-se a importância do geotêxtil que pro- tegeu $57 \%$ da superfície do solo, destacando-se suas propriedades inerentes ao tecido vegetal que retiveram à água, mantendo a umidade superficial no solo, indispensável à germinação das sementes das braquiárias. A vegetação incipiente ofereceu pouca proteção ao solo, mas reduziu a superfície exposta. Tem-se também o início do processo de biodegradação, que decompõem os geotêxteis. 
Figura 3 - Classificação supervisionada indicando a proteção dos geotêxteis na superfície do solo (Fase 1).

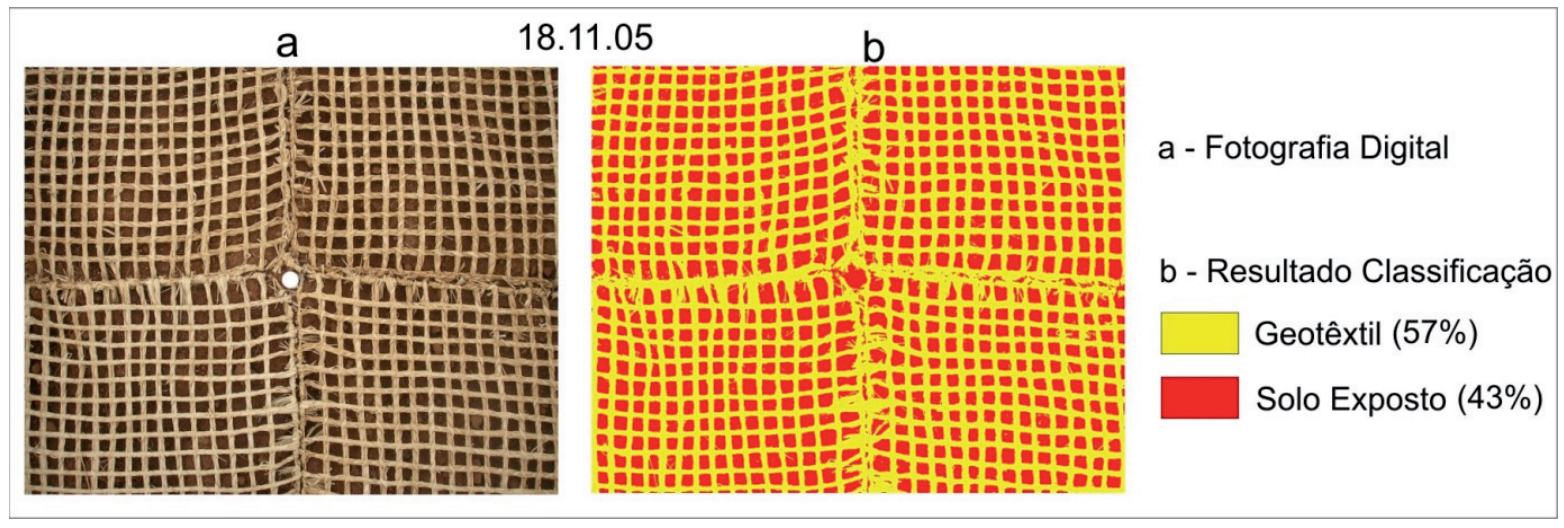

Autoria: BEZERRA, J. F. R, 18.11.05.

A ação combinada dos geotêxteis com a incipiente cobertura vegetal não influenciou os dados de tensiometria, pois se mantiverem praticamente próxi- mos aos dados da parcela com solo exposto, na qual não foi implantada nenhuma técnica de proteção da superfície (Quadro 2).

Quadro 2 - Potencial matricial e cobertura vegetal na estação experimental (SE - Solo

Exposto, SG - Solo geotêxtil e gramínea)

\begin{tabular}{|c|c|c|c|c|c|c|c|c|c|c|}
\hline Data & Vegetação & Chuva & $\begin{array}{l}120 \\
\mathrm{~cm} \\
\mathrm{SE}\end{array}$ & $\begin{array}{l}120 \\
\text { cm } \\
\text { SG }\end{array}$ & $\begin{array}{l}\mathbf{8 0} \\
\mathbf{c m} \\
\mathrm{SE}\end{array}$ & $\begin{array}{l}\mathbf{8 0} \\
\mathbf{c m} \\
\mathrm{SG}\end{array}$ & $\begin{array}{l}\text { 30 } \\
\text { cm } \\
\text { SE }\end{array}$ & $\begin{array}{l}\text { 30 } \\
\text { cm } \\
\text { SG }\end{array}$ & $\begin{array}{l}15 \\
\mathrm{~cm} \\
\mathrm{SE}\end{array}$ & $\begin{array}{l}15 \\
\text { cm } \\
\text { SG }\end{array}$ \\
\hline \multicolumn{11}{|c|}{ Fase 1 - Geotêxteis (kPa) } \\
\hline 18.11 & 0 & 3.03 & -19.75 & -20.6 & -15.05 & -7.6 & -11.6 & -8.05 & -11.55 & -10.5 \\
\hline 04.12 & 1.077 & 214.5 & -19 & -19 & -2 & -2 & -5 & -7 & -8 & -8 \\
\hline 15.12 & 4.429 & 118.12 & -15 & -15 & -5 & -7 & -7 & -6 & -8 & -7 \\
\hline 19.12 & 6.399 & 10 & -20 & -8 & -8 & -8 & -13 & -11 & -15 & -11 \\
\hline \multicolumn{11}{|c|}{ Fase 2 - Geotêxteis e gramíneas (kPa) } \\
\hline 26.12 & 15.247 & 68.12 & -20 & -13 & -2 & -5 & -4 & -4 & -3 & -12 \\
\hline 30.12 & 22.243 & 4.07 & -11 & -11 & -7 & -4 & -13 & -6 & -10 & -13 \\
\hline 03.01 & 30.745 & 13.03 & -21 & -22 & -11 & -6 & -12 & -15 & -8 & -13 \\
\hline 08.01 & 47.124 & 87 & -20 & -21 & -9 & -9 & -10 & -12 & -7 & -11 \\
\hline 12.01 & 50.383 & 21.4 & -19 & -19 & -7 & -9 & -6 & -8 & -9 & -11 \\
\hline 15.01 & 59.445 & 0.2 & -18 & -21 & -13 & -13 & -9 & -24 & -18 & -32 \\
\hline \multicolumn{11}{|c|}{ Fase 3 - Gramíneas (kPa) } \\
\hline 20.01 & 63.877 & 0 & -22 & -24 & -16 & -20 & -10 & -67 & -24 & -6 \\
\hline 24.01 & 73.536 & 3 & -22 & -26 & -10 & -22 & -9 & -21 & -28 & -14 \\
\hline 29.01 & 80.77 & 8 & -22 & -28 & -8 & -9 & -10 & -63 & -11 & -67 \\
\hline 31.01 & 86.732 & 32 & -23 & -24 & -3 & -12 & -4 & -6 & -8 & -9 \\
\hline 05.02 & 91.645 & 39.8 & -23 & -25 & -6 & -21 & -10 & -15 & -12 & -17 \\
\hline 13.02 & 95.645 & 84.6 & -23 & -24 & -4 & -8 & -9 & -31 & -12 & -36 \\
\hline 18.02 & 100 & 7.6 & -22 & -19 & -9 & -33 & -8 & -5 & -13 & -16 \\
\hline
\end{tabular}

Org. do autor.

A segunda fase de estudo da relação entre o potencial matricial e a cobertura vegetal, caracteriza-se pela ação combinada dos geotêxteis e das gramíneas. $\mathrm{O}$ período teve início no dia 26 de dezembro de 2005, com uma taxa de ocupação da cobertura vegetal de 15,2\% na área amostral e finalizado no dia 15 de janeiro de 2006, com uma taxa de ocupação de 59,4 \% (Figura 4). Nesse período foram registrados $193.8 \mathrm{~mm}$ de chuvas. Nessa etapa, destaca-se a proteção parcial da vegetação contra o impacto das gotas de chuvas e escoamento superficial, 
bem como uma maior infiltração decorrente do sistema radicular. Os dados de potenciais matriciais começam a apresentar significativa poro-pressão negativa, como por exemplo, o tensiômetro de $15 \mathrm{~cm}$ na parcela com geotêxtil e gramínea, que no dia 15 de janeiro de 2006 atinge $-32 \mathrm{kPa}$ (Quadro 2).

Figura 4 - Fotocomparação com visualização dos geotêxteis e gramíneas (Fase 2).

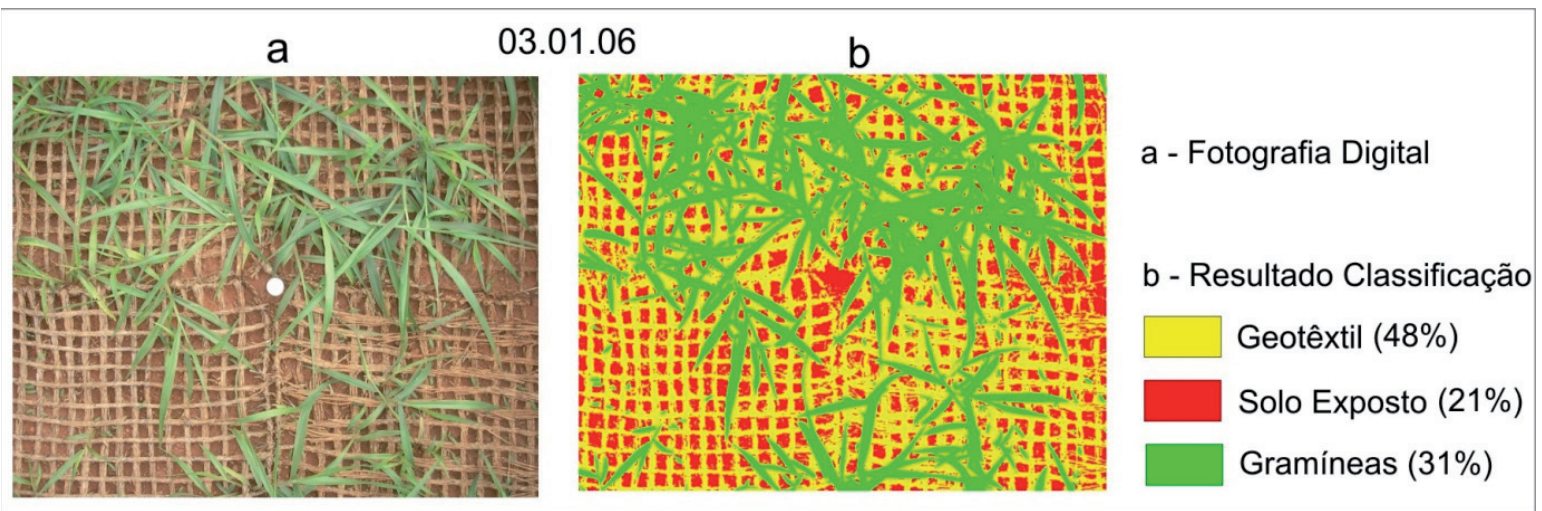

Autoria: BEZERRA, J. F. R, 18.11.05.

A terceira fase sobre as relações em questão remete a influência da cobertura de gramíneas sob os dados, quando comparado à parcela com solo exposto. Essa etapa inicia-se no dia 20 de janeiro de 2006 com uma taxa de ocupação da gramínea de $63,9 \%$ e finalizada no dia 30 de março de 2006. É importante ressaltar que no dia 18 de fevereiro de 2006, a cobertura vegetal atinge $100 \%$ de ocupação do ponto amostral, de acordo com a classificação supervisionada (Figura 5). Os totais pluviométricos foram de $175 \mathrm{~mm}$. Essa etapa caracteriza-se pela significativa ocupação das gramíneas, enquanto os geotêxteis e a superfície exposta têm um importante decréscimo porcentual.
Esta fotografia foi obtida no período de estiagem de janeiro, o que culminou na diminuição da umidade no solo, que ficou retida nos poros cada vez menores, culminando no ponto de murchamento da vegetação e menores pressões negativas (Quadro 2). Nesse caso, a vegetação influência diretamente nos dados de tensiometria, através da interceptação das gotas de chuva, e conseqüente aumento da infiltração pelos sistemas radicular, substituindo completamente a função do geotêxtil na proteção do solo.

Figura 5 - Fotocomparação com visualização parcial das gramíneas encobrindo os geotêxteis e protegendo o solo (Fase 3).

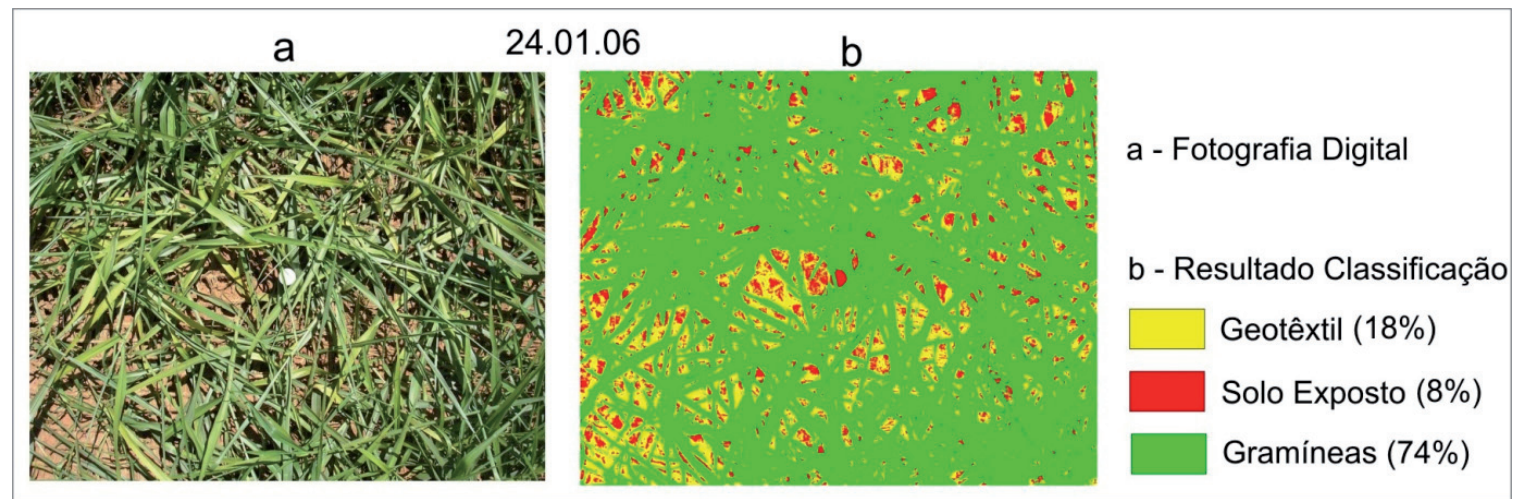

Autoria: BEZERRA, J. F. R, 24.01.06. 
Os potenciais matriciais a $15 \mathrm{~cm}$ variaram entre $-0,11 \mathrm{kPa}$ no dia 11 de dezembro de 2005 com $31 \mathrm{~mm}$ de chuva (Fase 1) e -67,1 kPa em 26 de janeiro de 2006 após duas semanas de estiagem e com $3 \mathrm{~mm}$ de chuvas (Fase 3). Nesse ponto, percebe-se a forte influência das raízes da braquiária, através da forte sucção propiciadas pelo sistema radicular. Tendo em vista todas as profundidades dos tensiômetros no experimento, é na profundidade de $15 \mathrm{~cm}$ que a influência dos geotêxteis sobre o potencial matricial deveria ser percebida, o que não ocorre, mantendo-se os dados praticamente próximos à saturação no período entre a aplicação da geotêxtil e do crescimento das gramíneas, ficando seu papel a nível secundário (Figura 6).

A maior amplitude do potencial matricial no sistema solo com geotêxteis foi encontrada na profundidade de $30 \mathrm{~cm}$, variando entre $-0,3 \mathrm{kPa}$ no dia 08 de dezembro de 2005 (Fase 1) com $32 \mathrm{~mm}$ de chuva (incipiente cobertura vegetal) e - $70,9 \mathrm{kPa}$ no dia $20 \mathrm{de}$ janeiro de 2006 após 1,5 semana de estiagem (Figura 7 - Fase 3). Esse baixo potencial matricial $(-70,9 \mathrm{kPa})$, ocorreu devido as melhores condições de circulação da água no solo, através de uma maior permeabilidade e sucção proporcionadas pelos sistemas radiculares das gramíneas que influenciaram diretamente o comportamento do fluxo da água no perfil do solo e que pode ser visualizado nos dados obtidos na classificação supervisionada.

Os resultados indicam também de forma indireta o crescimento das raízes e sua influencia sobre os resultados. Essa "marcha" das raízes, pode ser comprovada no tensiômetro de $80 \mathrm{~cm}$, aonde a menor pressão negativa chegou a $-51,2 \mathrm{kPa}$ no dia 23 de fevereiro de 2006 (Fase 3), um mês depois que os tensiômetros de 15 e $30 \mathrm{~cm}$ registraram esses valores (Figura 8). Os dados sobre o crescimento da cobertura vegetal demonstraram uma forte relação entre área de ocupação da gramínea (maior quantidade de raízes) e o potencial matricial. As gramíneas começaram a interferir nos resultados de poro pressão, quando atingiram $60 \%$ de ocupação da área amostral na parcela com geotêxteis e gramíneas, principalmente nas profundidades de 15 e $30 \mathrm{~cm}$.

Estudos realizados no município de Bananal (SP) por Leão et al (2003) apontam à importância da analise dos tensiômetros mais superficiais $(10-15 \mathrm{~cm})$, onde existe uma grande densidade de raízes. $\mathrm{O}$ autor destaca também nesse estudo, a diminuição da carga de pressão no solo, devido ao aumento do consumo de água pela malha de raízes, como também o aumento da infiltração.

Segundo Coelho Netto (2001, p. 117) as raízes têm importante participação na estruturação física dos solos, ampliando a capacidade de transmissão de água. As raízes no topo dos solos permitem a injeção de água em poucos minutos após a água atravessar o dossel e antes mesmo de preencher o déficit de água da serrapilheira.

A elevada amplitude dos valores de carga de pressão na parcela com geotêxteis ocorreu devido à expansão do sistema radicular das braquiárias, conforme a fotocomparação, ocasionando um grande consumo de água. Os potenciais matriciais a $120 \mathrm{~cm}$ de profundidade não apresentaram valores significativos quando comparados aos outros tensiômetros, variando entre $-6,7 \mathrm{kPa}$ (4 mm, dia 30.12.05 - Fase 2) e -28,1 kPa (39 $\mathrm{mm}$, dia 02.02.06 - Fase 3), tendo pequena diferenciação de amplitude em relação aos dados de $120 \mathrm{~cm}$ na parcela com solo exposto (Figura 9).

No tocante a influência das gramíneas sobre os dados de potencial matricial, os estudos de Costa et al (2005) indicam que na profundidade de $15 \mathrm{~cm}$, ocorreu uma variação de $-3 \mathrm{kPa}$ e foi registrado um processo de drenagem, demonstrando que na profundidade superficial, os sistemas radiculares influenciaram o comportamento do fluxo de água no solo.

Estudos realizados por LELES et al (2004) sobre a taxa de drenagem em parcelas sem cobertura vegetal e com gramíneas, discorrem que numa chuva de $20 \mathrm{~mm}$ nos sistemas, ambos alcançaram à saturação na profundidade mais superficial. Entretanto observa-se uma drenagem quase duas vezes maior na parcela com gramíneas em relação à parcela sem cobertura. Isto decorre tanto pelo efeito da sucção das raízes das plantas, como no melhoramento nas condições físicas do solo.

Na parcela com solo exposto, os valores médios de carga de pressão estão mais próximos à satura- 
Figura 6 - Relação do potencial matricial $(15 \mathrm{c} \mathrm{m})$ e respectiva cobertura do solo superficial pelo crescimento da vegetação de gramínea (SE - Solo exposto - SG - Solo geotêxteis).

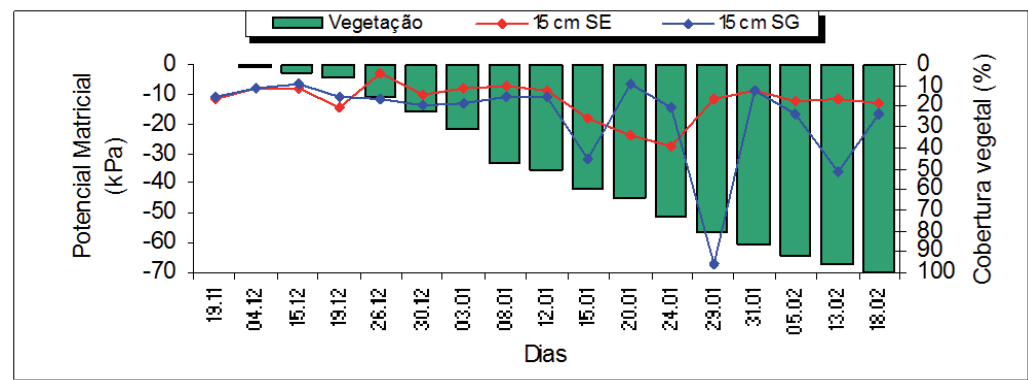

Org. do autor.

Figura 7 - Relação do potencial matricial $(30 \mathrm{~cm})$ e respectiva cobertura do solo superficial pelo crescimento da vegetação de gramínea (SE - Solo exposto - SG - Solo geotêxteis).

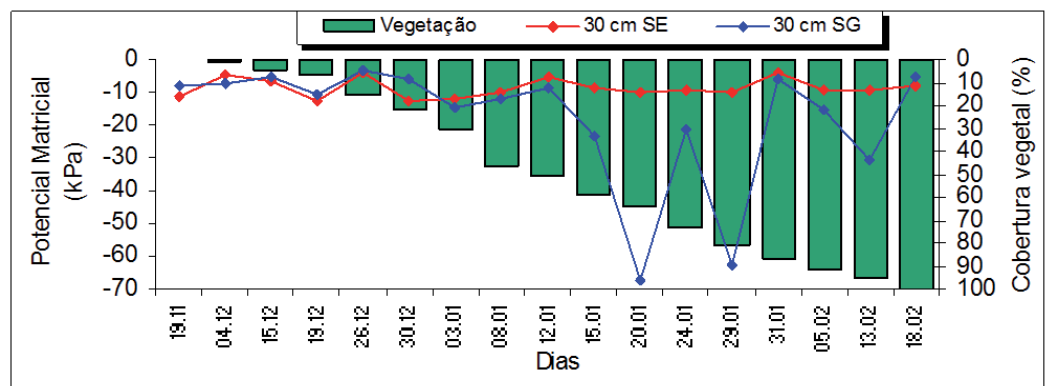

Org. do autor.

Figura 8 - Relação do potencial matricial $(80 \mathrm{~cm})$ e respectiva cobertura do solo superficial pelo crescimento da vegetação de gramínea (SE - Solo exposto - SG - Solo geotêxteis).

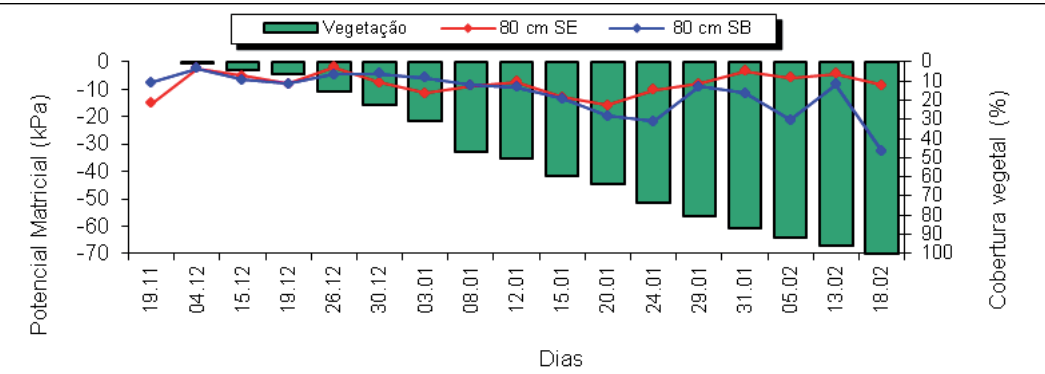

Org. do autor.

Figura 9 - Relação do potencial matricial $(120 \mathrm{~cm})$ e respectiva cobertura do solo superficial pelo crescimento da vegetação de gramínea (SE - Solo exposto - SG - Solo geotêxteis).

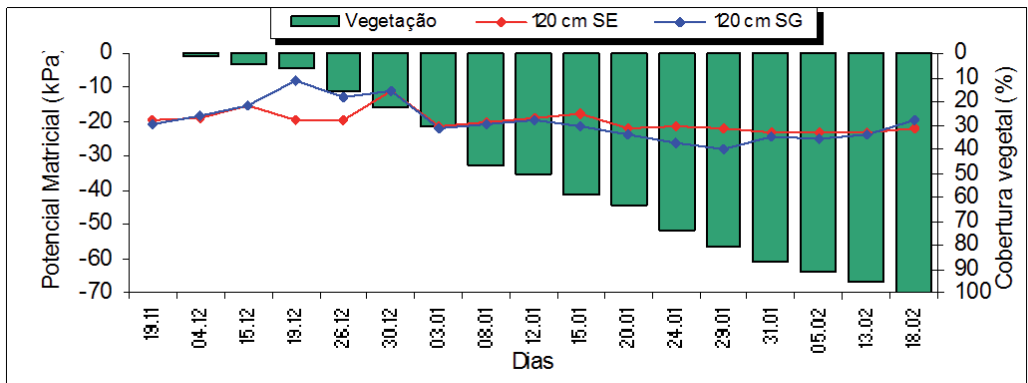

Org. do autor. 
ção que a parcela com a geotêxtil, atingindo $-10,1 \mathrm{kPa}$ $(15 \mathrm{~cm}),-7,6 \mathrm{kPa}(30 \mathrm{~cm})-6,8 \mathrm{kPa}(80 \mathrm{~cm}) \mathrm{e}-19,1 \mathrm{kPa}$ $(120 \mathrm{~cm})$.

A ausência de uma cobertura vegetal no solo pode acelerar a formação de crostas pelo efeito da compactação em função do splash, reduzindo rapidamente a infiltração. Esses efeitos podem ser melhores percebidos em solos argilosos, que podem ser mais facilmente compactados quando comparados aos solos arenosos, que são menos susceptíveis ao processo de compactação. Um mesmo efeito pode ser produzido pelos animais em áreas de pastagens ou pelo tráfico de veículos em trechos rodoviários não pavimentados.

Costa et al (2005) pesquisando o potencial matricial em uma parcela sem cobertura vegetal, a partir de ensaios com tensiômetros, discorre que essa parcela demorou 4:30 h para variar de $-6,5$ a $-0,6 \mathrm{kPa}$ na profundidade de $15 \mathrm{~cm}$, enquanto que, na profundidade de $30 \mathrm{~cm}$, foram registradas significativas variações após 4:30 h de experimento, onde registrou-se a variação de $-6,5$ a $-3,9 \mathrm{kPa}$, nas duas horas finais de ensaio. Os autores ainda concluem que esses dados refletem o grau de compactação da camada superficial da parcela sem cobertura vegetal que pode está acarretando efeitos nas propriedades físicas, e consequentemente, dificultando as condições de infiltração.

Nessa parcela (solo exposto), os dados estão mais próximos da poropressão positiva, que indica um solo mais saturado que o sistema com geotêxteis e gramíneas. Segundo Guerra \& Guerra (1997, p. 501) a poropressão é considerada positiva quando o solo está saturado, e a força capilar é neutralizada. Para os autores (1997, p. 501), durante um evento chuvoso os poros existentes no solo são preenchidos de água, e as forças de capilaridade decrescem, diminuindo também a capacidade de infiltração do solo, resultando na formação do escoamento superficial.

\section{CONSIDERAÇÕES FINAIS}

A fotocomparação com a classificação supervisionada permitiu acompanhar o desenvolvimento da cobertura vegetal, bem como as suas relações com o potencial matricial na parcela com geotêxteis e gramíneas. Os geotêxteis foram eficientes na diminuição do fluxo superficial e no controle do processo erosivo, ora servindo de obstáculo para a geração do escoamento superficial e reforçando o solo contra erosão, ora absorvendo a umidade, sendo essas informações registradas nos tensiômetros em diferentes profundidades.

Os dados de potencial matricial fornecidos pelos tensiômetros nas diferentes profundidades, mostraram uma estreita relação entre a distribuição da poro-pressão no solo com a geração do escoamento superficial. A parcela como solo exposto apresentou valores próximos à saturação da água, onde se registrou o maior escoamento superficial e conseqüente transporte de sedimento em relação com o sistema como geotêxteis e gramíneas.

A diferença de poro-pressão entre os pontos estudados, depende de uma série de fatores, dentre eles a presença de micro e macroporos no solo, a evaporação e absorção de água nas zonas onde estão as raízes das plantas. A soma desses fatores gera diferenças no potencial matricial ocasionando a movimentação hídrica no perfil, dos pontos de maior pressão negativa (elevada umidade) para zonas de menor pressão negativa (baixa umidade). Essa diferença pode ser observada na parcela com geotêxteis, tendo como parâmetro o antes e depois do desenvolvimento da cobertura vegetal.

\section{Agradecimentos}

À Coordenação de Aperfeiçoamento de Pessoal de Nível Superior pela bolsa de Doutorado.

Essa pesquisa constitui parte do Projeto Borassus "As contribuições ambientais e socioeconômicas dos geotêxteis feitos com folhas de palmeiras para atingir-se o desenvolvimento sustentável e a conservação dos solos" (INCO-CT-2005-510745), patrocinado pela Comissão Européia (CE), Programa de Projetos de Pesquisa com Objetivos Específicos (FP6 - STREPs) para Países em Desenvolvimento (INCO-DEV).

\section{REFERÊNCIAS}

AZEVEDO, M. M., LEITE, L. L., BAPTISTA, G. M. de M. The use of digital photographs to quantify vegetation ground cover in degraded areas. Sociedade \& Natureza. Uberlândia, 2005. 
CARRIJO, B. R., BACCARO, C. A. D. Análise sobre a erosão hídrica na área urbana de Uberlândia (MG). Caminhos de Geografia 1(2)70-83, dez/2000.

BUCKMAN \& BRADY. Natureza e propriedades dos solos. Ed. Freitas Bastos, Rio de Janeiro, 1976.

BEZERRA, J. F. R. Avaliação de geotêxteis no controle da erosão superficial a partir de uma estação experimental, Fazenda do Glória-MG. Dissertação (Mestrado). Universidade Federal de Uberlândia. Instituto de Geociências. Programa em Pós-Graduação em Geografia. 104 p, 2006.

COELHO NETTO, A. L. Hidrologia e sua interface com a Geomorfologia. In: Geomorfologia: uma atualização de bases e conceitos. $3^{\mathrm{a}}$ ed. Guerra, A. J. T. \& Cunha, S. B. Bertrand Brasil, Rio de Janeiro, 2001, p. 149-209.

COELHO, S. L. \& TEIXEIRAA. dos S. Avaliação do tensiômetro eletrônico no monitoramento do potencial matricial de água no solo. Engenharia. Agrícola, Jaboticabal, v.24, n.3, set./dez. 2004.

COSTA, A. R. C. et al. Condutividade Hidráulica in situ e sua relação com o potencial matricial em parcelas de erosão com diferentes usos. In: XI Simpósio Brasileiro de Geografia Física Aplicada. São Paulo, 2005.

CRISPIM, S. M. A\& BRANCO, O. D. Aspectos gerais das Braquiárias e suas Características na Sub-Região da Nhecolândia, Pantanal. In: Boletim de Pesquisa e Desenvolvimento - EMBRAPA. Corumbá, 2002.

EMBRAPA. Manual de Métodos e Análises Solo. Rio de Janeiro, EMBRAPA/SNLCS (1979).

GUERRA, A. T. \& GUERRA, A. J. T. Novo Dicionário Geológico-Geomorfológico. Bertrand Brasil, Rio de Janeiro, 1997, 648p.
LEÃO, O. M. da R; LEAL, P. J.; PREZA, D.M. \& COELHO NETO, A. L. Condicionantes geo-hidroecológicos de voçorocamentos em cabeceiras de drenagem, Bananal - SP. In: X Simpósio de Geografia Física Aplicada . Rio de Janeiro, 2003.

LELES, C. M. D., et al. Potencial Matricial e sua relação com os processos erosivos em parcelas com diferentes usos - Campus Experimental da UERJ. http://www.labgeoffp.com.br/PDF/res-Con-Cien-solo. pdf. 2004.

PINTO, N.L.S et al., Hidrologia Básica, Edgar Blücher, São Paulo, 1976.

REICHARDT, Klaus. Processos de transferência no sistema solo-planta-atmosfera. Fundação Cargil, São Paulo, 1985.

TAUK, Sâmia Maria. Biodegradação de resíduos orgânicos no solo. Revista Brasileira de Geociência 20(1-4):299-301, março/dezembro de 1990.

TRICART, J. P. Geomorphology for development and development for Geomorphology. In: International Geomorphology. John Wiley \& Sons. University of Manchester, 1986. 